\title{
Effect of Rood's approach in diabetic polyneuropathy.
}

\author{
Brinda R Patel ${ }^{1 *}$, Namrata Kadam², Pratik Pawar ${ }^{1}$ \\ ${ }^{1}$ Department of Physiotherapy, Krishna Institute of Medical Sciences, India \\ ${ }^{2}$ Department of Paediatrics, Krishna Institute of Medical Sciences, India
}

\begin{abstract}
Background: Diabetic neuropathy is the commonest complication of DM, affecting $47 \%$ patients with peripheral neuropathy. Rood's Approach is a neurophysiological approach which is based on reflexes of central nervous system. Basic concept of Rood's is that the motor patterns are developed from primitive reflexes through proper sensory stimuli to appropriate sensory receptors in normal sequential developmental pattern to improve motor performance.

Objectives: The objectives of the study were as follows:

1. To find effect of rood's approach in sensory abnormalities.

2. To find effect of rood's approach in muscle weakness.

Methods: Ethical clearance was obtained from the institutional ethical committee. A total of 23 diabetic neuropathy subjects were assessed and 20 were included in this study based on inclusion criteria, the individuals were allocated in one group: This group received Rood's approach, depending upon patients' condition either facilitatory or inhibitory techniques was given. Diabetic neuropathy was diagnosed using Michigan Neuropathy Screening Instrument Questionnaire and Pre- and post-test were done for assessing severity of diabetic neuropathy using Visual Analogue Scale (VAS), Quantitative Sensory Testing (QST) and Walking Impairment Questionnaire (WIQ) and the outcome measures were analysed after 3 months.

Results: Within the group statistical analysis, Pre-Post VAS score was $6.43 \pm 1.628$ and was extremely significant, Pre-Post QST score was $1.900 \pm 1.553$ and result was extremely significant and Pre-Post WIQ score was $19.150 \pm 2.978$ was also significant.

Conclusion: We found that facilitatory techniques of Rood's Approach (Quick stretch and heavy joint compression) were effective in improving decreased sensations and improving motor performance in patients with painful diabetic polyneuropathy. We found that inhibitory techniques of Rood's Approach (Maintained stretch and light joint compression) were effective in decreasing hypersensitivity in patients with painful diabetic polyneuropathy. We found significant improvement in pain measure (VAS), Sensory measure (Quantitative Sensory Testing) and Motor Performance Measure (Walking Impairment Questionnaire).
\end{abstract}

Keywords: Diabetic neuropathy, Rood's approach, VAS, QST, WIQ.

Abbreviations:

VAS: Visual Analogue Scale, QST: Quantitative Sensory

Testing, WIQ: Walking impairment Questionnaire.

Accepted on March 19, 2019

\section{Introduction}

\section{Diabetic neuropathy}

It is the commonest complication of DM, affecting $47 \%$ patients with peripheral neuropathy. Cutaneous sensation is mediated by superficial receptors and deep sensation is mediated by deep receptors [1]. Touch pressure sensation of non-hairy skin is mediated by Meissner corpuscles and Pacinian corpuscles respond to vibratory stimuli [2].

Mechanism of injury/pathological process: Total hyperglycaemic exposure, elevated lipids, smoking, increased height, high exposure to neurotoxic agents, genetic factors.

Clinical presentation: Motor symptoms in upper limbs-Distal motor symptoms which include fine hand co-ordination (pincer 
grasp), in lower limbs- Mild drop foot or frequent tripping due to lower limb weakness.

Sensory symptoms: Slow, sudden onset sensory neuropathy showing stocking and glove distribution in distal extremities [3].

Negative sensory symptoms: Feeling of numbness or deadness, loss of balance, especially with eyes closed and painless injuries due to loss of sensation [4].

Positive sensory symptoms: Burning, prickling pain, tingling, aching and tightness.

\section{Staging of diabetic polyneuropathy:}

- $\mathrm{NO}$ - No Neuropathy

- N1a - Signs but no symptoms of neuropathy

- $\quad \mathrm{N} 2 \mathrm{a}$ - Symptomatic mild Diabetic Polyneuropathy

- $\quad \mathrm{N} 2 \mathrm{~b}$ - Severe symptomatic Diabetic Polyneuropathy

- N3 - Disabling Diabetic Polyneuropathy

Diagnostic procedures: Testing includes assessment of gross light touch and pinprick sensation. First clinical sign develops in diabetic symmetrical sensorimotor polyneuropathy is reduction of vibratory and pinprick sensation over the toes. Sensory loss occurs in stocking and glove appearance. Vibratory sensation is tested. Deep Tendon Reflexes are assessed [5-7].

Medical management: Anticonvulsant - Pregabalin, Antidepressant - Duloxetine, Opioids - Dextromethorphan.

Physiotherapy options available for diabetic neuropathy: TENS, Infra-red lamp, aerobic and resistance training, lifestyle changes. It is found in earlier studies that TENS is effective in reducing pain in Diabetic Neuropathy [8-10]. Research also shows that aerobic and resistance training causes significant reduction in pain in painful diabetic neuropathy $[3,11]$. However, there is limited research in physical therapy options in painful diabetic neuropathy treating both motor and sensory components.

\section{Rood's approach}

Rood's approach is a neurophysiological approach which is based on reflexes of central nervous system. Basic concept of Rood's is that the motor patterns are developed from primitive reflexes through proper sensory stimuli to appropriate sensory receptors in normal sequential developmental pattern to improve motor performance. The basic principles of Rood's approach are normalisation of tone, ontogenic developmental sequence, purposeful movement and repetition or practice.

Rood's approach includes of various facilitatory and inhibitory techniques. The facilitatory and inhibitory techniques used in this study are:

Facilitatory techniques: Quick stretch and heavy joint compression (in cases with decreased sensation).
Inhibitory techniques: Maintained stretch and light joint compression (in cases with increased sensation) [11,12].

\section{Facilitatory techniques}

Quick stretch: Stretch is a physiologic stimulus which is used to activate the proprioceptors in selected muscles of the body. Quick stretch employs principles of reciprocal innervation. The muscle undergoing stretch was facilitated. Quick stretch was applied by holding the proximal bony prominences of the limb to be stretched while moving the distal joint in one direction.

Heavy joint compression: Heavy joint compression is defined as joint compression greater than applied through the longitudinal axis of the bone. The amount of force was more than that of the normal body weight above the supporting joint. It was used to facilitate co contraction at the joint undergoing compression. This approach can be combined with developmental patterns.

\section{Inhibitory techniques}

Maintained stretch: Positioning hypertonic extremities in the elongated position for various periods to cause lengthening of the muscle spindles. Rood recommended maintained stretch in the lengthened position for the stronger agonist muscle to increase the threshold of muscle spindle and antagonist muscle was then facilitated by cutaneous stimulation to offset the muscle imbalance.

These contractions were done repeatedly with no resistance and with gravity eliminated, spasticity was reduced.

Light joint compression: Joint compression of body weight or less than body weight was used to inhibit spastic muscles around a joint.

In diabetic neuropathy, there are positive as well as negative sensory symptoms. Negative sensory symptoms include feeling of numbness or deadness, loss of balance, especially with eyes closed and painless injuries due to loss of sensation. While positive sensory symptoms include burning, prickling pain, tingling, aching, tightness. Even there is muscle weakness along with this sensory loss. As Rood's Approach is a neurophysiological approach which is based on reflexes of central nervous system and basic concept of Rood's is that the motor patterns are developed from primitive reflexes through proper sensory stimuli to appropriate sensory receptors in normal sequential developmental pattern to improve motor performance [10]. It even includes facilitatory and inhibitory techniques and including the principle motor output is dependent on sensory input there are chances that facilitatory techniques will be beneficial in improving sensory loss and inhibitory techniques will lead to decreased hypersensitivity and this sensory output will in turn improve motor performance.

Thus, there is a need to find effectiveness of Rood's Approach on sensory as well as motor complaints in individuals with diabetic neuropathy. 


\section{Materials and Methods}

Ethical clearance was obtained from the institutional ethical committee. A total of 23 diabetic neuropathy subjects were assessed and 20 were included in this study based on inclusion criteria which included diabetic neuropathy subjects, pain, age 40-75 years, motor and sensory symptoms and having diabetes since 10 years, the individuals were allocated in one group. This group received Rood's Approach, depending upon patients' condition either facilitatory or inhibitory technique was given. Diabetic neuropathy was diagnosed using Michigan Neuropathy Screening Instrument Questionnaire and Pre- and post-test were done for assessing severity of diabetic neuropathy using Visual Analogue Scale (VAS), Quantitative sensory testing (QST) and Walking Impairment questionnaire (WIQ) and the outcome measures were analysed after 3 months.

Sampling method: Cluster sampling method.

The study included only one group. Pre-intervention Michigan Neuropathy Screening Instrument Questionnaire score was used to diagnose patients with diabetic neuropathy. Pre-test and post-test pain measure (VAS score), Quantitative Sensory Testing and Walking Impairment Questionnaire was used to assess the patients. Rood's Approach-(3 days/week for 3 months) (5 reps).

Facilitatory techniques: Quick stretch and heavy joint compression, Inhibitory techniques-Maintained stretch and light joint compression.

\section{Results}

Primary outcomes used for the result were VAS, QST and WIQ.

\section{Gender distribution in the study}

The gender distribution is shown in Figure 1.

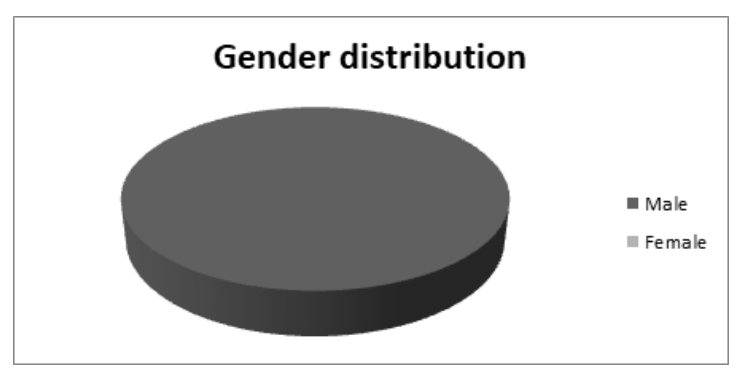

Figure 1. The pie diagram represents that out of 20 subjects, 20 males and 0 females have participated in this study.

\section{Age groups}

The age group and frequency are noted in below Tables 1 and 2 and Figures 2 and 3.

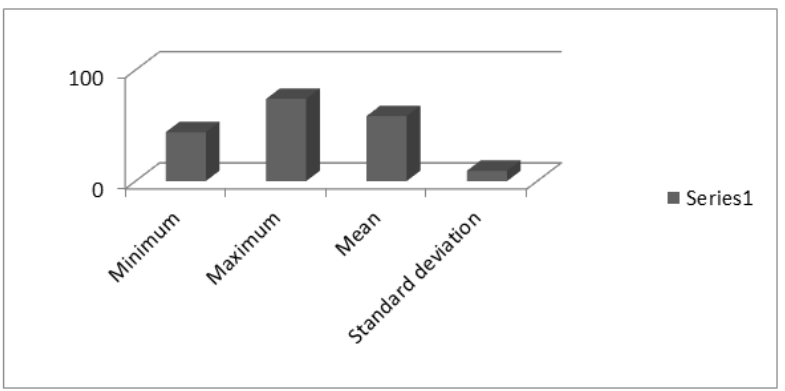

Figure 2. The age group included in this study is 40-75 years. The table and graph shows that minimum age group in the study is 44 years and maximum is 74 years. The mean of the age group is 58.5 years and standard deviation is 9.288 .

Table 1. Age of the individuals and data.

\begin{tabular}{llll}
\hline Minimum & Maximum & Mean & Standard deviation \\
\hline 44 & 74 & 58.5 & 9.288 \\
\hline
\end{tabular}

Table 2. Age group and frequencies.

\begin{tabular}{lll}
\hline Age group & Frequency & Percentage \\
\hline$\leq 60$ & 11 & $55 \%$ \\
\hline$>60$ & 9 & $45 \%$ \\
\hline
\end{tabular}

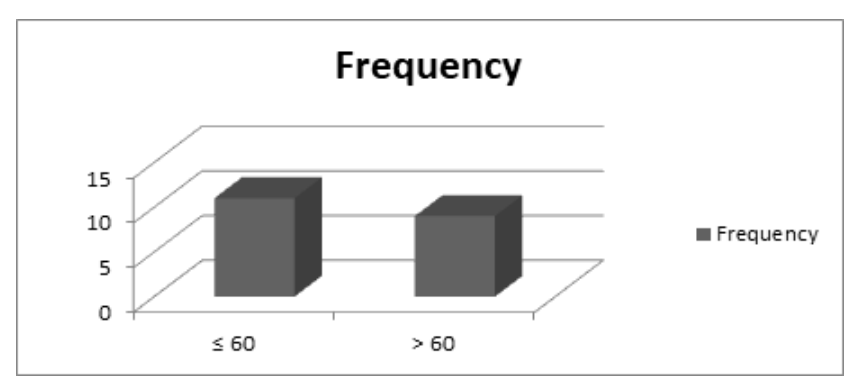

Figure 3. The graph indicates that out of 20 males, 11 males are in the age group $\leq 60$ years and remaining 9 males are in age group $>$ 60 years.

\section{Chief complaint}

The chief complaints are noted in below Table 3 and Figure 4.

Table 3. The chief complaints and frequency of individuals.

\begin{tabular}{lll}
\hline Chief complaint & Frequency & Percentage \\
\hline Difficulty in walking & 1 & $5 \%$ \\
\hline Difficulty in moving hand & 1 & $5 \%$ \\
\hline Pain in left leg & 2 & $10 \%$ \\
\hline Pain in right leg & 5 & $25 \%$ \\
\hline Pain in right foot & 1 & $5 \%$ \\
\hline Burning sensation & 2 & $10 \%$ \\
\hline Pain in both legs & 6 & $30 \%$ \\
\hline
\end{tabular}




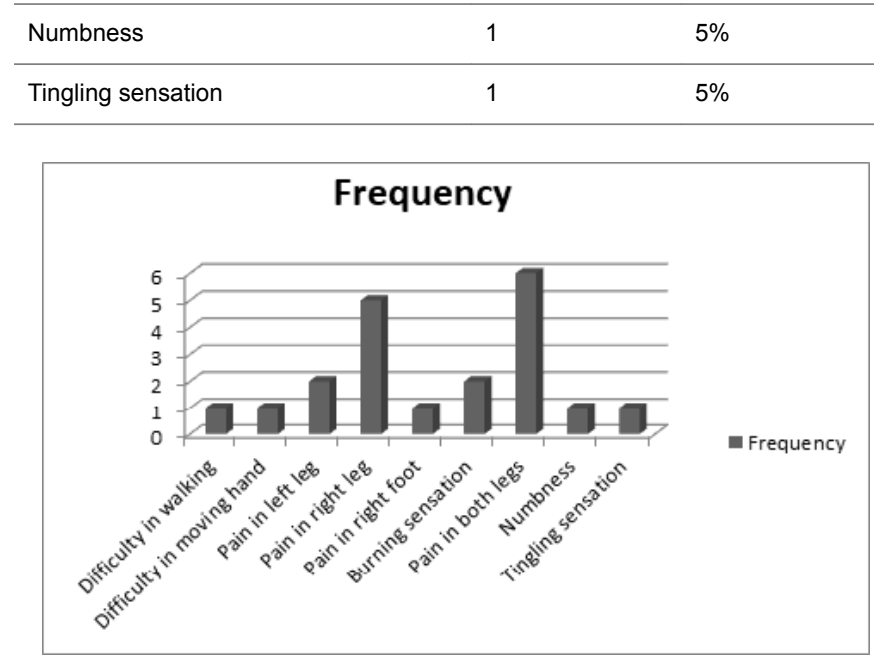

Figure 4. The above table and graph indicates the frequency of each chief complaint in the entire study.

\section{Duration of chief complaint}

The duration of the chief complaints, its mean and standard deviation are shown in Table 4 and Figure 5.

Table 4. Mean and standard deviation of the data.

\begin{tabular}{llll}
\hline Minimum & Maximum & Mean & Standard deviation \\
\hline 5 & 100 & 36 & 29.151 \\
\hline
\end{tabular}

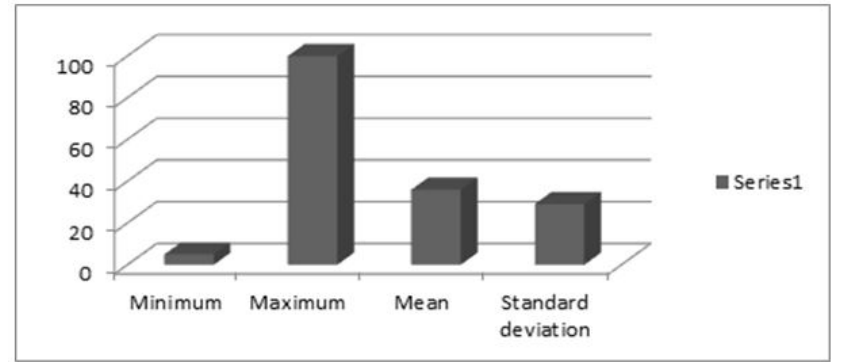

Figure 5. The above figure and graph represents the duration since chief complaint has occurred. Minimum duration is 5 days and maximum duration is 100 days. Mean of duration of chief complaint since it has occurred is 36 days and standard deviation is 29.151.VAS.

\section{Quantitative sensory testing}

Pre-Post QST Score: Table 5 shows pre and post comparison of VAS scores. The paired mean difference between pre and post VAS scores is 6.43 and standard deviation is 1.628 . Tvalue is 4.053 and $p$ value is 0.0007 and there was extremely significant decrease in pain score. Table 6 indicates pre and post comparison of QST score. The paired mean difference between pre and post QST scores is 1.900 and standard deviation is 1.553 . T-value is 5.473 and $p$ value is $<0.0001$ and there was extremely significant improvement in sensation.

Table 5. The table shows pre and post comparison of VAS score.

\begin{tabular}{|c|c|c|c|c|c|c|c|}
\hline \multicolumn{8}{|c|}{ Paired sample t Test } \\
\hline \multirow{3}{*}{ VAS } & \multicolumn{5}{|c|}{ Paired Differences } & $\mathbf{T}$ & Significance (2-tailed) \\
\hline & \multirow[t]{2}{*}{ Mean } & \multirow[t]{2}{*}{ Std. deviation } & \multirow[t]{2}{*}{ Std. error mean } & \multicolumn{2}{|c|}{$\begin{array}{l}95 \% \text { Confidence } \\
\text { Interval of the } \\
\text { difference }\end{array}$} & & \\
\hline & & & & Lower & Upper & & \\
\hline Pre VAS-Post VAS & 6.43 & 1.628 & 0.36408 & 0.7132 & 2.237 & 4.053 & 0.0007 \\
\hline
\end{tabular}

Table 6. The table indicates pre and post comparison of QST score.

\begin{tabular}{|c|c|c|c|c|c|c|c|}
\hline \multicolumn{8}{|c|}{ Paired sample $t$ test } \\
\hline \multirow{3}{*}{ QST } & \multicolumn{5}{|c|}{ Paired differences } & $\mathbf{T}$ & Significance (2-tailed) \\
\hline & \multirow[t]{2}{*}{ Mean } & \multirow[t]{2}{*}{ Std. deviation } & \multirow[t]{2}{*}{ Std. error mean } & \multicolumn{2}{|c|}{$\begin{array}{l}95 \% \text { confidence } \\
\text { interval of the } \\
\text { difference }\end{array}$} & & \\
\hline & & & & Lower & Upper & & \\
\hline Pre QST-Post QST & 1.9 & 1.553 & 0.3472 & 2.627 & 1.173 & 5.473 & $<0.0001$ \\
\hline
\end{tabular}

\section{Walking impairment questionnaire}

Pre-Post WIQ score: Table 7 indicates pre and post comparison of WIQ score. The paired mean difference between pre and post QST scores is 19.150 and standard deviation is 2.978. T- value is 28.754 and $p$ value is $<0.0001$ and there was extremely significant improvement in walking post treatment. 
Table 7. The table indicates pre and post comparison of WIQ score.

\begin{tabular}{|c|c|c|c|c|c|c|c|}
\hline \multicolumn{8}{|l|}{ Paired sample $t$ test } \\
\hline \multirow{3}{*}{ WIQ } & \multicolumn{5}{|c|}{ Paired Differences } & \multirow[t]{2}{*}{$\mathbf{T}$} & \multirow[t]{2}{*}{ Significance (2-tailed) } \\
\hline & Mean & Std. deviation & Std. error mean & $\begin{array}{l}95 \% \quad \text { c } \\
\text { interva } \\
\text { differer }\end{array}$ & & & \\
\hline & & & & Lower & Upper & & \\
\hline Pre WIQ- Post WIQ & 19.15 & 2.978 & 0.666 & 20.544 & 17.756 & 28.754 & $<0.0001$ \\
\hline
\end{tabular}

\section{Discussion}

Painful neuropathy is the most disabling complication of diabetes and it occurs due to peripheral nerve damage. Peripheral Nervous system is affected in both types of diabetes mellitus. Pathophysiology of painful diabetic polyneuropathy is unknown but trials have shown that good glycaemic control reduces occurrence of complications [13]. Several studies have shown that conventional treatment did not show any improvement in painful diabetic polyneuropathy $[5,14]$. In 2016, Kamaljeet Singh reported that D1 and D2 patterns of PNF for 3 days/week for 3 months were effective in treating both motor and sensory components. It improved sensorimotor control in patients with diabetic polyneuropathy.

In 2013, Patricia M K reported that 10-week of aerobic and strengthening exercise training caused significant reduction in pain $(-18.1+35.5 \mathrm{~mm})$, neuropathic symptoms $(-1.24+1.8)$ and increased intraepidermal nerve fiber branching $(+0.11 \pm 0.15)$.

In this exercise intervention study, we found that while the participants perceived pain, sensory abnormalities and muscle weakness from diabetic peripheral neuropathy did not change with medications, but they felt less hindered in certain aspects of their life by the painful neuropathy after 8 weeks of facilitatory or inhibitory techniques of Rood's Approach. The small size of our sample limits interpretation of this study. This successful engagement of previously inactive and chronically debilitated population in a routine 8 week exercise programme suggests that supervised treatment are viable in people with diabetic polyneuropathy, while also posing a question regarding whether results have differed with greater adherence to intervention of greater duration.

Our findings show significant reduction in how the participants reported that their diabetic neuropathy pain interfered with their daily activities. A significant reduction in average pain interference scale reveals that the intervention may have played role on the impact of pain on quality of life. The participants may have experienced improvement in sensory abnormalities and muscle strength and have experienced less distress and increased confidence in walking.

This study did not address any physiological changes that occurred during or after the intervention. We observed significant changes after giving Rood's approach for 3 days/ week for 3 months in VAS score (pain intensity), Quantitative sensory testing (sensory abnormalities) and Walking impairment questionnaire (motor performance). The therapeutic methods studied here were well tolerated associated with any serious adverse effects. The results of this study support previous findings and indicate Rood's approach is effective in treating both motor and sensory components. Large multi-center randomised, controlled trials with longer duration of treatment are needed to evaluate the efficacy of these procedures [15-20].

\section{Conclusion}

We found that facilitatory techniques of Rood's Approach (Quick stretch and heavy joint compression) were effective in improving decreased sensations and improving motor performance in patients with painful diabetic polyneuropathy. We found that inhibitory techniques of Rood's Approach (Maintained stretch and light joint compression).

We found that facilitatory techniques of Rood's Approach (Quick stretch and heavy joint compression) were effective in improving decreased sensations and improving motor performance in patients with painful diabetic polyneuropathy. We found that inhibitory techniques of Rood's Approach (Maintained stretch and light joint compression) were effective in decreasing hypersensitivity in patients with painful diabetic polyneuropathy. We found significant improvement in pain measure (VAS), Sensory measure (quantitative sensory testing) and Motor performance measure (walking impairment questionnaire).

\section{Acknowledgement}

We would like to acknowledge the guidance and support of Gayatri Patane and Ankita Patil from faculty of physiotherapy.

\section{Authors' Contributions}

Brinda Ramesh Patel conducted literature review for this manuscript, developed introduction section of the manuscript together with the discussion of the study findings, collected data, and analysed the data. Namrata Kadam provided the description of the background information and participated in preparation of the manuscript. 


\section{Conflict of Interest}

The author declares that there are no conflicts of interest concerning the content of the present study.

\section{References}

1. Dyck PJ, Herrmann DN, Staff NP, Dyck PJ. Assessing decreased sensation and increased sensory phenomena in diabetic polyneuropathies. Diabetes 2013; 62:3677-3686.

2. Romero CF, Sadidi M, Feldman EL. Mechanisms of disease: The oxidative stress theory of diabetic neuropathy. Rev Endocr Metab Disord 2008; 9:301-314.

3. Singh R, Gamble G, Cundy T. Lifetime risk of symptomatic carpal tunnel syndrome in Type 1 diabetes. Diabet Med 2005; 22:625-630.

4. Shaw JE, Zimmet PZ. The epidemiology of diabetic neuropathy. Diabetes Reviews 1999; 7:245-252.

5. Quan D, Lin CH. Diabetic Neuropathy Clinical Presentation 2019.

6. Hamza MA, White PF, Craig WF, Ghoname ES, Ahmed HE, Proctor TJ, Noe CE, Vakharia AS, Gajraj N. Percutaneous electrical nerve stimulation: a novel analgesic therapy for diabetic neuropathic pain. Diabetes Care 2000; 23:365-370.

7. Bhosale A, Thangavelu DP. Effect of lifestyle modification in type II diabetes mellitus individuals. AJPCR 2019; 12:381-383.

8. Bordoloi K, Deka RS. Scientific Reconciliation of the concepts and principles of Rood Approach. IJHSR 2018; 8:225-234.

9. Malik RA. Which test for diagnosing early human diabetic neuropathy? Diabetes 2014; 63:2206-2208.

10. YP Munjal. API textbook of medicine. Jaypee Brothers Medical Publishers, India. 2015:2.

11. Wendy Walker, Sheikh Abdul Khadir. Diabetic neuropathy. Physiopedia.

12. Kerstin MP, Andeela H. Neuropathic pain. Physiopedia.
13. Bahram NN, Abbas S, Mohammad H, Gelareh B. Comparison of transcutaneous electrical nerve stimulation and pulsed radiofrequency sympathectomy for treating painful diabetic neuropathy. Anesth Pain Med 2015; 5.

14. Kamaljeet S, Lalit A, Reena A. Effect of proprioceptive neuromuscular facilitation in improving sensorimotor function in patients with diabetic neuropathy affecting lower limbs. IJPHY 2016; 3:332-336.

15. Nizar A, Nishad AL. Effects of multisensory training on balance and gait in persons with type 2 diabetes: A randomised controlled trial. DCID 2013; 24.

16. Shahanawaz SD. Effect of high TENS on neuropathic pain in diabetic neuropathy patients. Int J Physiother Res 2014; 2:604-607.

17. Patricia MK, Pasnoor M, Singh R. The Effect of exercise on neuropathic symptoms, nerve function, and cutaneous innervation in people with diabetic peripheral neuropathy. J Diabetes Complications 2013; 26:424-429

18. Tofthagen C, Visovsky C, Berry LD. Strength and balance training for adults with peripheral neuropathy and high risk of fall: current evidence and implications for future research. Onco Nursing Forum 2017; 39:416-424

19. Yoo M, D'Sliva L, Martin K, Sharma N, Pasnoor M, Master J, Kluding MP. Pilot study of exercise therapy on painful diabetic peripheral neuropathy. Pain Med 2015; 16:1482-1489.

20. Susan BO. Sullivan Physical rehabilitation. Jaypee Brothers Medical Publishers, India. 2014; 14:577-634.

\section{*Correspondence to}

Brinda R Patel

Department of Physiotherapy

Krishna Institute of Medical Sciences

India 